\title{
PESQUISA EM EDUCAÇÃO AMBIENTAL E CULTURAS NO EPEA
}

\author{
José Artur Barroso Fernandes ${ }^{1}$ \\ Celso Sánchez Pereira ${ }^{2}$ \\ Andre Carneiro $\mathrm{Melo}^{3}$ \\ Danilo Seithi Kato ${ }^{4}$ \\ Rosileia Oliveira de Almeida ${ }^{5}$
}

\section{Resumo}

Este artigo tem por objetivo refletir sobre algumas questões levantadas no Grupo de Discussão de Pesquisas (GDP) Educação ambiental e culturas, durante o IX Epea - Encontro Pesquisa em Educação Ambiental, realizado em Juiz de Fora, no ano de 2017. Para além de trazer um relato das discussões, o artigo se debruça sobre a evolução das temáticas dos trabalhos relacionados a culturas, apresentados nas cinco últimas edições do EPEA, em um pequeno estado da arte realizado por meio de termos de busca ligados à temática, presentes em seus resumos. Percebe-se que, nas edições de 2009, 2011 e 2013 predominavam, entre os textos que traziam a palavra cultura em seus resumos, trabalhos ligados aos estudos culturais, particularmente abordando aspectos ligados aos discursos que se relacionam com as questões ambientais, presentes nas mídias e na sociedade. Nas duas últimas edições, de 2015 e 2017, nota-se o aumento do número de trabalhos abordando questões como interculturalidade, diálogo de saberes e decolonialidade, possibilitando identificar possíveis desdobramentos epistemológicos presentes no campo da pesquisa em educação ambiental articulada ao debate em torno das questões culturais.

Palavras-chave: Educação Ambiental. Culturas. Pesquisa.

\section{RESEARCH ON ENVIRONMENTAL EDUCATION AND CULTURES AT EPEA}

\begin{abstract}
This article aims to develop some issues raised in the Environmental Education and Cultures Research Group (GDP) during the IX Epea - Research Meeting on Environmental Education, held in Juiz de Fora in 2017. In addition to providing an account of the discussions, the article focuses on the evolution of themes related to culture and presented in the last five editions of the EPEA, in a small state of the art made through search terms related to the theme, present in their abstracts. It is observed that in the 2009, 2011 and 2013 editions, among the texts that brought the word culture in their summaries, works related to the field of cultural studies predominated, particularly addressing aspects related to the discourses that relate to environmental issues, present in the media and society. In the last two editions, in 2015 and 2017, there is an increase in the number of papers addressing issues such as interculturalism, dialogue of knowledge and decoloniality, making it possible to identify possible epistemological developments in the field of environmental education articulated to the debate on cultural issues.
\end{abstract}

Keywords: Environmental Education. Cultures. Research.

\footnotetext{
${ }^{1}$ Professor na Universidade Federal Fluminense. E-mail: josef@id.uff.br

${ }^{2}$ Professor na Universidade Federal do Estado do Rio de Janeiro. E-mail: celso.sanchez@ hotmail.com

${ }^{3}$ Doutorando na Universidade Federal da Bahia. E-mail: acmbio@yahoo.com.br

${ }^{4}$ Professor na Universidade Federal do Triângulo Mineiro. E-mail: katosdan@yahoo.com.br

${ }^{5}$ Professora na Universidade Federal da Bahia. E-mail: rosileiaoalmeida@ hotmail.com
} 


\section{PESQUISA EN EDUCACIÓN AMBIENTAL Y CULTURAS EN EL EPEA}

\section{Resumen}

Este artículo tiene por objetivo desarrollaralgunascuestiones surgidas enel Grupo de Discusión de Investigaciones (GDP) Educación ambiental y culturas, durante el IX Epea Encuentro Pesquisa enEducación Ambiental, realizado en Juiz de Fora, enelaño 2017. Además de traerun relato de lasdiscusiones, el artículo se centra enlaevolución de las temáticas de lostrabajos relacionados conla cultura, presentados enlas cinco últimas edicionesdel EPEA, enunpequeño estado del arte realizado por medio de términos de búsqueda relacionados a la temática, presentes en sus resúmenes. Se percibe que enlasediciones de 2009, 2011 y 2013 predominaban, entre los textos que traíanlapalabra cultura en sus resúmenes, trabajos relacionados al campo de losestudiosculturales, particularmente abordando aspectos ligados a los discursos que se relacionanconlascuestionesambientales, medios y enlasociedad. Enlasdos últimasediciones, de 2015 y 2017, se observa el aumento del número de trabajos abordando cuestiones como interculturalismo, diálogo de saberes y la decolonialidad, posibilitando identificar posiblesdesdoblamientos epistemológicos presentes enel campo de lainvestigación de la educación ambiental articulada al debate en torno a lascuestionesculturales.

Palabras clave: Educación Ambiental. Culturas. Investigación.

\section{Introdução}

O presente artigodesenvolve uma reflexão sobre a natureza dos trabalhos apresentados no EPEA- Encontro Pesquisa em Educação Ambiental, no âmbito doGrupo de Discussão de Pesquisas (GDP) Pesquisa em Educação Ambiental e Culturas.

Nas discussões desenvolvidas durante o IX Epea, realizado em Juiz de Fora (MG), no ano de 2017,os participantes do GDP manifestaram inquietação com o fato de que havia apenas seis trabalhos associados a esse GDP quando de suas inscrições no evento, o que nos levou a questionar se o número de trabalhos relacionados a temáticas que envolvem cultura era realmente pequeno ou se haveria outros trabalhos com aderência ao GDPPesquisa em Educação Ambiental e Culturascujos autores optaram por submetê-los a GDPs de outras temáticas.

Essa hipótese parecia fazer sentido, já que um trabalho do campo dos estudos culturais, por exemplo, que se desenvolvesse em contextos não escolares de educação ambiental, teria, nessa edição do Epea, dois GDPs diretamente relacionados, dado que também havia um GDP intitulado Pesquisa em Educação Ambiental e Contextos Não Escolares,sendo que seu autor teria que optar por submeter o trabalho a apenas um dos dois grupos de discussão.

Assim, durante o GDP do IX Epea, fizemos um exercício coletivo de buscar, entre todos os trabalhos do evento, aqueles que traziam a palavra cultura em seus resumos. Dessa busca resultaram 23 trabalhos, cujos resumos foram lidos pelos participantes do GDP para identificar quais deles traziam questões mais centrais ligadas a aspectos culturais e quais se relacionavam a outras temáticas, trazendo a palavra culturaapenas em contextos incidentais. Encontramos, assim,onze estudos centrados nas questões de cultura, o que ia além dos seis trabalhos iniciais, e passamos a analisar quais as temáticas principais abordadasnesses trabalhos.

Apesar da limitação de tempo de trabalho durante o GDP, conseguimos identificar, nesse conjunto de textos, as seguintes temáticas: diálogo de saberes (os quais o grupo identificou como aqueles que traziam questões em torno das temáticas indígenas, 
quilombolas, culturas urbanas, mulheres e semiárido); aportes do campo dos estudos etnicorraciais na EA; aportes da Educação do Campo para a EA; impactos na EA de epistemologias do Sul e decolonialidade; relações entre cultura e justiça ambiental, bem como aportes do campo da ecologia política e da justiça ambiental.

Tendo em vista a abordagem de novas temáticas nesses trabalhos do IX Epea, em relação àquelas contempladas no VII Epea, realizado em Rio Claro, que correspondeu à primeira edição do evento em que tivemos o GDP Pesquisa em Educação Ambiental $e$ Culturas, que traziam um recorte mais definido nos chamados estudos culturais, resolvemos promover uma reflexão inicial sobre a evolução das temáticas dos trabalhos relacionados a culturaspresentes nas últimas cinco edições do Epea.

\section{O GDP Pesquisa em Educação Ambiental e Culturas}

O GDP Pesquisa em Educação Ambiental e Culturas foi realizado, pela primeira vez, no VII Epea, em Rio Claro, sob a coordenação da professoraLúcia de Fátima Estevinho Guido, no ano de 2013. Nessa primeira edição do Epea em que o GDP Culturasesteve presente, oito trabalhos foram submetidos ao GDP, abordando as temáticas: fotografia, mídia, cultura e arte. Quatro deles traziam o termo fotografia em suas palavras-chave, e três traziam o termomídia. Quinze participantes estiveram presentes no primeiro dia, e dezesseis, no segundo.

Durante as discussões, os participantes caracterizaram o GDP a partir da seguinte ementa, que foi apresentada na sessão de síntese:

Este GDP tem a preocupação de reunir as pesquisas que fazem interlocução com a cultura e seus processos de produção nos museus, nas artes visuais, nos cotidianos, nas mídias, na fotografia, na literatura, no cinema e nas intervenções artísticas a partir de diferentes campos teóricos como os estudos culturais; as perspectivas pósestruturalistas; pós-modernas e as filosofias da diferença (GUIDO, 2013, s/p)

O relato da discussão apontou que as marcas encontradas nas pesquisas inscritas foram a linguagem autoral, a pesquisa como processo de constante indagação e os seguintes referenciais teóricos principais: Michel Foucault, Félix Guattari, Isabel Carvalho, Gilles Deleuze, Marcos Reigota, AlikWunder, Rosa Maria B. Fischer, Maria Lucia Wortmann, Valdo Barcellos, Rolland Barthes, Stuart Hall, Lucia Santaella, Susana Dias, Martine Joly (GUIDO, 2013).O conjunto de temáticas e de seus principais referenciais apontava, então, para a confluência dos Estudos Culturais com a Educação Ambiental.

Em artigo publicado na Revista Pesquisa em Educação Ambiental, que reuniutextos referentes ao VII Epea, Guimarães eWortmann (2014) examinam a emergência de algumas vinculações postuladas sobre a articulação entre Educação Ambiental e Estudos Culturais, que foi o tema de uma mesa-redonda do evento. No artigo, os autores apresentam trabalhos que focalizam diferentes produções da cultura, na linha de pesquisa Estudos Culturais e Educação no PPG/Educação da UFRGS, apontando significados atribuídos à natureza, bem como algumas formas de representá-la.Tais trabalhos faziam parte de um primeiro conjunto de estudos que visavam

[...] examinar, em diferentes instâncias e produções da cultura, relações entre natureza e cultura, objetivando estender essa compreensão ao entendimento de como se estabelecem, preferencialmente, e até mesmo se cristalizam, em determinadas épocas, certas formas de configuração de problemáticas ambientais (GUIMARÃES; WORTMANN, 2014, p.29).

Ainda segundo Guimarães e Wortmann (2014, p. 29), um segundo grupo de trabalhos, que além de se orientarem por tais preocupações se ocupavam "também, e talvez até mais 
intensamente, com questões relacionadas a produções identitárias", investigavam a produção de sentidos sobre textos que impactaram os diversos discursos contemporâneos relativos às disputas em torno do tema natureza. A partir dessas considerações, otrabalho aponta desdobramentos variados em pesquisas na interface entre os Estudos Culturais e a Educação Ambiental, em contextos formativos provenientes da psicologia social, da mídia-educação, da análise do discurso.Os autores apontam o "compromisso, ao mesmo tempo político e poético, dos estudiosos da cultura com certa escuta atenta, delicada, minoritária e sensível das práticas culturais que nos atravessam e nos enredam no tempo presente" (GUIMARÃES; WORTMANN, 2014, p.34).

No ano de 2015, o Epea passou por uma mudança significativa, deixando de ser realizado apenas no eixo paulista de UNESP, UFSCar e USP ${ }^{6}$, universidades que sediaram todas as sete edições iniciais do evento. Quando passou a ser realizado em outros estados, o Epea passou a abarcar públicos diferentes, dando mais espaço para perspectivas de pesquisa em Educação Ambiental afinadas com os grupos locais que passaram a organizar o evento. $\mathrm{O}$ primeiro estado a sediar o Epea, nessa nova fase, foi o Rio de Janeiro, com a realização do VIII Epea.

O GDP Pesquisa em Educação Ambiental e Culturas foi coordenado, no VIII Epea, pelo professor Marco Antonio Leandro Barzano, com o apoio do professor José Artur Barroso Fernandes. Onze participantes estiveram presentes nas sessões de discussão.

Nove submissões de trabalhos foram vinculadas ao GDP, sendo que os autores de cinco desses trabalhos estiveram presentes nas discussões do grupo. As temáticas das pesquisas desenvolvidas em tais trabalhos, bastante variadas, enfocavaminvestigaçõesque estudaramcausos e relações entre educação ambiental e saberes populares, pesquisas situadas na interface entre Arte-Educação e Educação Ambiental, estudos de produções midiáticas e pesquisas que abordavam outros recortes culturais, como os significados produzidos por comunidades indígenas sobre a infância.

A discussão caminhou no sentido de buscar os espaços da pesquisa em EA em sua articulação com os estudos culturais, dentro do contexto mais amplo das produções atuais da área, apontando a centralidade, para os participantes, de perspectivas que ampliassem as análises para além das categorias construídas pelas teorias críticas.

Nas discussões, partindo da ideia de que toda sociedade produz cultura, de que os grupos estudados produzem cultura, percebeu-se uma demanda dos participantes por uma aproximação aos estudos culturais, particularmente em perspectivas pós-estruturalistas. $\mathrm{O}$ grupo apontou que, quando temas socioambientais são levados para dentro da escola, há diversas vozes, de diversas culturas entrelaçadas, questionando características da EA crítica que tem se consolidado como hegemônica - as quaispoderiam estar impedindo que as questões culturais e artísticas fossemincorporadas na EA.

Tomando as culturas como redes de significados, no sentido de Geertz (1989), como seria possívelpensar a EA com consciência das questões relacionadas, por exemplo, às relações de poder e à luta de classes, sem consideraro recorte da EA Crítica?Ou ainda, dialogando com esse recorte?

Percebemos, aqui, que as discussões caminhavam no sentido de buscar uma articulação não apenas entre os Estudos Culturais e a Educação Ambiental, mas, também, entre as abordagens que têm sido feitas nas pesquisas com esse recorte e as demais agendas dominantes no cenário da Educação Ambiental, naquele momento.

Em 2017, sob a coordenação dos professores José Artur Barroso Fernandes e Celso Sánchez Pereira, o GDP Pesquisa em Educação Ambiental e Culturas tomou um caminho

\footnotetext{
${ }^{6}$ Universidade Estadual Paulista, campus Rio Claro, Universidade Federal de São Carlos e Universidade de São Paulo, campus Ribeirão Preto.
} 
diferente, dado que apenas seis trabalhos haviam sido submetidos ao GDP, dos quais apenas três tinham autores presentes nas discussões do grupo. As discussões do grupo contaram, no evento, com dez participantes.

Optou-se, nessa edição, por fazer uma discussão a partir da leitura dos resumos de todos os trabalhos aprovados no evento que traziam o termo de busca cultura em seus resumos, conforme já apresentado na introdução do presente artigo: 23 trabalhos foram recuperados, seus resumos foram impressos e os participantes os classificaram como pertencentes ou não à interface de estudos culturais e educação ambiental. Dessa classificação, resultaram onze trabalhos nas temáticas: diálogo de saberes (indígenas, quilombolas, culturas urbanas, mulheres, semiárido); aportes na Educação Ambiental(EA) dos estudos etnicorraciais; aportes na EA da Educação do Campo; contribuições das Epistemologias do Sul e da Decolonialidade para a EA; relações entre cultura e justiça ambiental, conforme explicado anteriormente.

Ao lidar com os trabalhos resultantes dessa seleção, identificamos novas temáticas relacionadas a linhas de pesquisa que se baseiam em referenciais ligados aos estudos de interculturalidade e decolonialidade. Assim, refinamos a seleção, utilizando novos termos de busca que pudessem recuperar, a partir do universo de trabalhos aprovados, mais trabalhos que se situavam na interface dos estudos sobre cultura e ambiente.

Os novos termos utilizados, no sentido de construir uma busca bastante ampla, foram:cultura;estudos culturais; discurso; comunicação; identidade; interculturalidade; multicultural (multiculturalidade, multiculturalismo); colonial (colonialidade, pós-colonial, pós-colonialismo, decolonialidade); saberes. Ainda assim, foram recuperados apenas seis novos trabalhos que não estavam entre os localizados pelo termo cultura, sendo que apenas um deles trazia uma temática diferente das que já haviam sido observadas, tratando das relações entre a cobertura das mídiassobre um desastre ambiental e a educação ambiental.

Como resultado desse exercício,observamos que as temáticas mais presentes na primeira edição de nosso GDP, mais ligadas às mídias e às artes, estavam pouco presentes entre os trabalhos submetidos ao IX Epeacomo um todo.

Isso nos levou a questionar se estaríamos assistindo a uma mudança nas temáticas dos trabalhos no Epea que articulam estudos culturais e educação ambiental, ou se seria apenas uma mudança circunstancial, talvez relacionada com a mudança no eixo geográfico de realização do evento.

Observando a lista de trabalhos submetidos ao GDP Pesquisa em Educação Ambiental e Culturas em suas primeiras três edições (Quadro 1), podemos perceber que, em 2013, havia forte predomínio de temas ligados às mídias e à fotografia. Já no VIII Epea, em 2015, ainda contando com estudos envolvendo mídias e fotografia, aparecem trabalhos lidando com narrativas orais e causos, dialogando com saberes populares, que nos parece ter sido a grande temática nesse GDP. Na edição mais recente do Epea, em 2017, foi privilegiado o olhar para o diálogo de saberes, contando, agora, com aportes dos referenciais de interculturalidade e das epistemologias do Sul.

\begin{tabular}{|l|l|l|l|}
\hline Edição & Título & Autor principal & palavras-chave \\
\hline \multirow{5}{*}{$\begin{array}{l}\text { VII Epea - } 2013 \\
\text { Educação ambiental e cultura: } \\
\text { modos de ser do sujeito no Rock } \\
\text { andRoll }\end{array}$} & $\begin{array}{l}\text { Virginia T. Vieira } \\
\begin{array}{l}\text { Educação ambiental e foto- } \\
\text { dispositivo: experimentando a a } \\
\text { fotografia como uma criação de } \\
\text { outros sentidos sobre uma } \\
\text { população tradicional }\end{array}\end{array}$ & $\begin{array}{l}\text { Griseambiental. } \\
\text { Rock and Roll. } \\
\text { Cultura. }\end{array}$ \\
\hline
\end{tabular}




\begin{tabular}{|c|c|c|c|}
\hline & $\begin{array}{l}\text { Composições entre arte e ciência: } \\
\text { "cicatrizes" da natureza uma } \\
\begin{array}{l}\text { contribuição } \\
\text { ambiental à }\end{array}\end{array}$ & $\begin{array}{lll}\text { Antonio } & \text { A. } & \text { da } \\
\text { Silva } & & \end{array}$ & $\begin{array}{l}\text { Fotografia. Ciência. } \\
\text { Educação } \\
\text { Ambiental. }\end{array}$ \\
\hline & $\begin{array}{l}\text { Olhares do bio-cotidiano: } \\
\text { experimentar fotografias através } \\
\text { da Educação Ambiental }\end{array}$ & $\begin{array}{lll}\text { Antonio } & \text { A. } & \text { da } \\
\text { Silva } & & \end{array}$ & $\begin{array}{l}\text { Educação } \\
\text { Ambiental. }\end{array}$ \\
\hline & 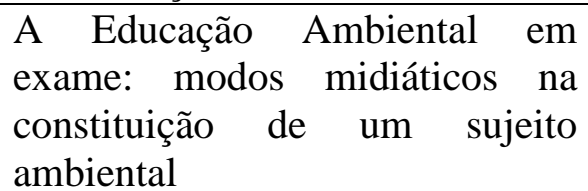 & Bárbara H. Garré & $\begin{array}{l}\text { Educação } \\
\text { Ambiental. Mídia. } \\
\text { Relações de poder. }\end{array}$ \\
\hline & $\begin{array}{l}\text { Relações de poder em } \\
\text { funcionamento: a educação } \\
\text { ambiental na mídia brasileira }\end{array}$ & Paula C. Henning & $\begin{array}{l}\text { Educação } \\
\text { Ambiental. Mídia. } \\
\text { Crise ambiental. }\end{array}$ \\
\hline & $\begin{array}{l}\text { Olhares perceptivos: usos e } \\
\text { sentidos da fotografia na } \\
\text { Educação Ambiental }\end{array}$ & LakshmiHofstatter & $\begin{array}{l}\text { Interpretação } \\
\text { fotográfica. Olhares } \\
\text { perceptivos. } \\
\text { Caatinga. }\end{array}$ \\
\hline & $\begin{array}{l}\text { Mídia e } \\
\text { representações de natureza na } \\
\text { publicidade }\end{array}$ & Marise B. Amaral & $\begin{array}{l}\text { Representação. } \\
\text { Natureza. Mídia. }\end{array}$ \\
\hline \multirow{7}{*}{$\begin{array}{l}\text { VIII Epea - } \\
2015\end{array}$} & $\begin{array}{l}\text { Os caminhos da educação } \\
\text { ambiental nos filmes de } \\
\text { animação: histórias contadas } \\
\text { pelas crianças pelo filme 'Rio' }\end{array}$ & $\begin{array}{lr}\text { Carolina } & \text { Alves } \\
\text { Gomes } & \text { de } \\
\text { Oliveira } & \end{array}$ & $\begin{array}{l}\text { Filmes de animação. } \\
\text { Estudos culturais. } \\
\text { Educação ambiental. }\end{array}$ \\
\hline & $\begin{array}{l}\text { Vozes das minhas vozes: causos } \\
\text { contados e encantados por } \\
\text { moradores do Povoado de } \\
\text { Alecrim Miúdo (BA) em um } \\
\text { diálogo com a Educação } \\
\text { Ambiental }\end{array}$ & $\begin{array}{l}\text { Damile de Jesus } \\
\text { Ferreira }\end{array}$ & $\begin{array}{lr}\text { Narrativas } & \text { orais. } \\
\text { Tradição } & \text { oral. } \\
\text { Educação } & \\
\text { Ambiental. } & \end{array}$ \\
\hline & $\begin{array}{l}\text { Lembranças e histórias de um } \\
\text { vale encantado: a educação } \\
\text { ambiental popular através da } \\
\text { metodologia investigação ação } \\
\text { participante (IAP) na proteção de } \\
\text { saberes locais no vale do } \\
\text { Jequitinhonha }\end{array}$ & $\begin{array}{ll}\text { Daniel } & \text { Renaud } \\
\text { Camargo } & \end{array}$ & $\begin{array}{l}\text { Investigação Ação } \\
\text { Participante. (IAP), } \\
\text { Educação Ambiental } \\
\text { Popular. Vale do } \\
\text { Jequitinhonha. }\end{array}$ \\
\hline & $\begin{array}{l}\text { Sertão e ficção: deslocamentos } \\
\text { poéticos por/entre imaginografias }\end{array}$ & $\begin{array}{l}\text { Gabriele Nigra } \\
\text { Salgado }\end{array}$ & $\begin{array}{l}\text { Sertão. Fotografia. } \\
\text { Ficção. } \quad \text { Educação } \\
\text { Ambiental. }\end{array}$ \\
\hline & $\begin{array}{l}\text { Causos de onça: uma } \\
\text { possibilidade de trabalho na } \\
\text { educação ambiental pela } \\
\text { elucidação de sentidos e conflitos } \\
\text { entre humanos e onças }\end{array}$ & LakshmiHofstatter & $\begin{array}{l}\text { Causos } r \text { de } \\
\text { onça.Conflitos entre } \\
\text { humanos e onças. } \\
\text { Educação } \\
\text { Ambiental. }\end{array}$ \\
\hline & $\begin{array}{l}\text { Naturezas e infâncias: as } \\
\text { diferentes experiências culturais }\end{array}$ & $\begin{array}{l}\text { Luana Santos da } \\
\text { Silva }\end{array}$ & $\begin{array}{l}\text { Naturezas. Infâncias. } \\
\text { Crianças indígenas. }\end{array}$ \\
\hline & A riqueza do imponderável: & Maíra & Educação \\
\hline
\end{tabular}




\begin{tabular}{|c|c|c|c|}
\hline & $\begin{array}{l}\text { complexidade e desafios da } \\
\text { Ciência,Tecnologia e Sociedade } \\
\text { e da Educação Ambiental em } \\
\text { rede }\end{array}$ & Ferrari & $\begin{array}{l}\text { Ambiental. } \\
\text { Sociedade em Rede. } \\
\text { Ciência Tecnologia } \\
\text { e Sociedade. } \\
\text { Pensamento } \\
\text { Complexo. }\end{array}$ \\
\hline & $\begin{array}{l}\text { Elos entre saberes culturais, } \\
\text { percepções, conhecimento e uso } \\
\text { dos recursos naturais. }\end{array}$ & $\begin{array}{l}\text { Maria Das Graças } \\
\text { Da Silva }\end{array}$ & $\begin{array}{l}\text { Saberes culturais } \\
\text { locais. } \\
\text { Territorialidades } \\
\text { ancestrais. } \\
\text { Biodiversidade. }\end{array}$ \\
\hline & $\begin{array}{l}\text { A imagem do homem sobre si } \\
\text { mesmo: uma aproximação com a } \\
\text { cultura oriental para se pensar a } \\
\text { Educação Ambiental e sua } \\
\text { Complexidade }\end{array}$ & $\begin{array}{ll}\text { Samuel } & \text { Lopes } \\
\text { Pinheiro } & \end{array}$ & $\begin{array}{l}\text { Complexidade. } \\
\text { Holograma. } \\
\text { Imagem. }\end{array}$ \\
\hline \multirow{6}{*}{$\begin{array}{l}\text { IX Epea- } \\
2017\end{array}$} & $\begin{array}{l}\text { Interculturalidade e educação } \\
\text { ambiental: Possibilidades e } \\
\text { desafios com a cultura Guarani } \\
\text { Mbyá }\end{array}$ & $\begin{array}{l}\text { Clara dos Santos } \\
\text { Baptista }\end{array}$ & $\begin{array}{lr}\text { Educação } & \\
\text { Ambiental. } & \\
\text { Educação } & \text { em } \\
\text { Ciências. } & \text { Temas } \\
\text { Geradores. } & \end{array}$ \\
\hline & \begin{tabular}{lcr} 
Saberes da & \multicolumn{2}{c}{ biodiversidade: } \\
tecendo trilhas & e traçando os \\
caminhos que & atravessam a \\
escola e o Sertão.
\end{tabular} & $\begin{array}{l}\text { André } \quad \text { Carneiro } \\
\text { Melo }\end{array}$ & $\begin{array}{l}\text { Ecologia de saberes. } \\
\text { Biodiversidade. } \\
\text { Semiárido. }\end{array}$ \\
\hline & $\begin{array}{ll}\text { A memória } & \text { e o } \\
\text { autoconhecimento nas } & \text { vivências } \\
\text { ambientais urbanas } & \text { enquanto } \\
\text { proposta educativa } & \\
\end{array}$ & $\begin{array}{l}\text { Lakshmi Juliane } \\
\text { VallimHofstatter }\end{array}$ & $\begin{array}{l}\text { Natureza urbana. } \\
\text { Memórias afetivas. } \\
\text { Autoconhecimento. }\end{array}$ \\
\hline & $\begin{array}{l}\text { As Discussões Acerca da } \\
\text { Sustentabilidade } \\
\text { Desenvolvimento Sustentável na } \\
\text { Perspectiva Intercultural: análise } \\
\text { da produção acadêmica a partir } \\
\text { do banco de teses do projeto } \\
\text { EArte }\end{array}$ & $\begin{array}{ll}\text { Rejane } & \text { Leal } \\
\text { Candido } & \end{array}$ & $\begin{array}{l}\text { Sustentabilidade. } \\
\text { Desenvolvimento } \\
\text { sustentável. } \\
\text { Educação ambiental. }\end{array}$ \\
\hline & $\begin{array}{l}\text { Educação Ambiental de Base } \\
\text { Comunitária no Vale do } \\
\text { Jequitinhonha: uma Articulação } \\
\text { entre a IAP de Fals Borda e a } \\
\text { Abordagem Temática Freireana }\end{array}$ & $\begin{array}{ll}\text { Daniel } & \text { Renaud } \\
\text { Camargo } & \end{array}$ & $\begin{array}{l}\text { Educação Ambiental } \\
\text { de } \\
\text { Comunitária. } \\
\text { Investigação Ação } \\
\text { Participante. } \\
\text { Abordagem } \\
\text { Temática Freireana. }\end{array}$ \\
\hline & $\begin{array}{l}\text { O encontro epistemológico e a } \\
\text { Chave de Harmonia: A juventude } \\
\text { urbana do Santo Daime e suas } \\
\text { interações na educação formal }\end{array}$ & $\begin{array}{l}\text { Evandro Cesar } \\
\text { Azevedo da Cruz }\end{array}$ & $\begin{array}{l}\text { Epistemologia do } \\
\text { Sul. Educação } \\
\text { Ambiental. Santo } \\
\text { Daime. }\end{array}$ \\
\hline
\end{tabular}

Quadro 1 - Trabalhos submetidos ao GDP Pesquisa em Educação Ambiental e Culturas nas três últimas edições do Epea. Fonte: os autores. 
Para aprofundar a compreensão, nos propusemos a realizar um rápido levantamento das temáticas situadas na interface entre Educação Ambiental e culturas que estavam presentes no Epea nas cinco últimas edições, partindo da ideia de usar termos de busca para identificar esses trabalhos entre todos os que constam nos anais dos eventos.

\section{Olhando para trás: ampliando o enfoque}

Realizamos uma investigação nos moldes do que Ferreira (2002) chama de estado da arte, que dirige um olhar inventariante e descritivo para a produção acadêmica,visando identificar quais aspectos e dimensões vêm sendo destacados e privilegiados em diferentes épocas e lugares.

Utilizamos, para esse fim, os anais das cinco últimas edições do Epea (de 2009 a 2017), buscando, nos resumos dos trabalhos aprovados, os seguintes termos de busca, identificados nas discussões do GDPPesquisa em Educação Ambiental $e$ Culturas:cultura;estudos culturais;discurso;comunicação; identidade; interculturalidade;multicultural (multiculturalidade, multiculturalismo); colonial (colonialidade, pós-colonial, pós-colonialismo, decolonialidade); saberes.

Esses termos foram escolhidos por estarem presentes nos resumos dos trabalhos submetidos ao GDP e por terem recuperado, no exercício que fizemos durante as discussões do GDP, trabalhos que não haviam sido recuperados a partir exclusivamente do termo cultura. O termo mídia também foi testado, por estar presente nas palavras-chave de três trabalhos de 2013, mas foi abandonado por retornar apenas dois trabalhos, nos cinco anos, que já haviam sido recuperados por outros termos.

O sistema de busca de trabalhos dos anais das três últimas edições do Epea possui a opção de palavra no resumo como tipo de busca, mas, para os eventos de 2009 e 2011, foi necessário construir uma planilha contendo os resumos dos trabalhos, pois os anais não oferecem essa possibilidade de busca.

Vale ressaltar que esse levantamento é interpretativo, pois nem sempre os termos utilizados retornam trabalhos que estejam no escopo de nosso GDP. O termo cultura, por exemplo, retornou um trabalho que citava o Ministério de Educação e Cultura em um trabalho claramente fora do escopo. Da mesma forma, o termo discurso, por vezes, era citado de forma incidental no resumo, embora não correspondesse ao tema central da investigação. Ainda nesse sentido, o termo saberes, por vezes, estava ligado a trabalhos que discutiam saberes docentes, em uma perspectiva de formação de professores. Nesses casos, os resumos foram descartados de nosso levantamento.

Dos termos utilizados, cultura foi o menos produtivo no sentido de mapear as linhas temáticas dos trabalhos, por ser excessivamente genérico dentro de nosso escopo. Assim, apresentamos nossos resultados na Tabela 1, expressos em número de trabalhos por edição do Epea, organizados para os demais termos de busca. A tabela mostra os trabalhos que entendemos pertencer ao escopo do GDP.

Tabela 1 - Número de trabalhos recuperadosportermo de busca e por edição do evento

\begin{tabular}{|l|l|l|l|l|l|l|l|l|}
\hline \multirow{2}{*}{$\begin{array}{l}\text { Ediçã } \\
\text { o do } \\
\begin{array}{l}\text { Epea } \\
$\cline { 2 - 8 }\end{array}\end{array}} & $\begin{array}{l}\text { Termos de busca } \\
\text { sultura } \\
\text { is }\end{array}$ & $\begin{array}{l}\text { discurs } \\
\text { o }\end{array}$ & $\begin{array}{l}\text { comunicaç } \\
\text { ão }\end{array}$ & $\begin{array}{l}\text { identida } \\
\text { de }\end{array}$ & $\begin{array}{l}\text { intercultur } \\
\text { al }\end{array}$ & $\begin{array}{l}\text { multicultur } \\
\text { al }\end{array}$ & $\begin{array}{l}\text { coloni } \\
\text { al }\end{array}$ & $\begin{array}{l}\text { sabere } \\
\text { s }\end{array}$ \\
\hline $\begin{array}{l}2009 \\
\text { Epea }\end{array}$ & 0 & 5 & 2 & 1 & 0 & 0 & 0 & 0 \\
\hline
\end{tabular}




\begin{tabular}{|l|l|l|l|l|l|l|l|l|}
\hline 5 & & & & & & & & \\
\hline $\begin{array}{l}2011 \\
\text { Epea } \\
6\end{array}$ & 2 & 5 & 6 & 3 & 0 & 0 & 0 & 3 \\
\hline $\begin{array}{l}2013 \\
\text { Epea } \\
7\end{array}$ & 2 & 7 & 1 & 0 & 0 & 0 & 0 & 2 \\
\hline $\begin{array}{l}\text { Epea } \\
8\end{array}$ & 1 & 4 & 1 & 4 & 2 & 1 & 1 & 5 \\
\hline $\begin{array}{l}2017 \\
\text { Epea } \\
9\end{array}$ & 0 & 4 & 1 & 1 & 3 & 0 & 2 & 6 \\
\hline
\end{tabular}

Fonte: os autores

Na Tabela 1 é possível identificar que o termo estudos culturais, associado aos estudos com o termo discurso, foram preponderantes nas duas primeiras edições do evento para o período analisado. No entanto, nota-se o aumento significativo dos trabalhos envolvendo os termos interculturale identidadeque não estavam entre os trabalhos submetidos no evento até 2015, sendo que nas duas últimas edições do evento identificou-se uma frequência relativamente alta, quando comparado aos outros termos no mesmo período. Há ainda o termo colonial com presença significativa, principalmente nos dois últimos eventos. O termo saberes também aparece somente a partir de 2011, sendo ausente no período anterior. São três trabalhos em 2011, chegando ao dobro desse número na última edição do evento.

Ao associar as buscas realizadas para o período, identificamos que o enfoque nos chamados estudos culturais vigorou de forma preponderante até a sétima edição do evento (2013), contudo, ao associar os termos intercultural e identidade, coloniale saberesnota-se uma mudança, do ponto de vista teórico. Como o termo discursopode ser vislumbrado em diferentes abordagens de pesquisa, infere-se que houve uma mudança, no evento referido, quanto ao posicionamento teórico. Nesse sentido, é importante delinear o contexto dos aspectos da interculturalidade e das teorias pós-coloniais que agregam as palavras encontradas nos trabalhos para as últimas edições do evento.

Podemos inferir que a educação ambiental é um campo de pesquisa permeável aos desdobramentos epistemológicos de outros campos como, por exemplo, o campo dos estudos culturais, que vão paulatinamente, incorporando as temáticas e os debates em torno da problematização do multiculturalismo e da proposta da interculturalidade, em particular dos aportes do chamado giro decolonial, que começam a ser incorporados nos trabalhos em educação ambiental mais recentemente.

Os estudos apontam que o referencial da Educação Ambiental Crítica pode estar sendo interpretado como uma abordagem que se distancia dos trabalhos que procuram incorporar a perspectiva da cultura na Educação Ambiental. Tal aspecto pode ser entendido como uma das razões para justificar a submissão de poucos trabalhos nesse GDP. Ressalta-se, ainda, o fato de que muitos trabalhos apresentados nas diferentes edições do Epea se caracterizam como adequados a diferentes GDPs, o que também poderia explicar essa baixa procura.

No entanto, os trabalhos do último Epea apontaram para uma ampliação das discussões em torno do campo dos estudos culturais, dos debates sobre interculturalidade, decolonialidade, diálogos/ecologias de saberes e epistemologias do Sul, mostrando que, apesar do número reduzido detrabalhos, verifica-se uma diversidade importante de temáticas que reforça a necessidade desse GDP e do estímulo à sua ampliação nos próximos Epeas. 
O período em foco no presente estudo envolve debates importantes no contexto da pesquisa da EA. Não são escassos os trabalhos e autores que se posicionaram, na última década, no sentido de indicar a necessidade de perspectivas ambientais menos eurocentradas, partindo das demandas e contradições ambientais desde o ponto de vista latino-americano (LEFF, 2011; LAYRARGUES; LIMA, 2011; GONZALEZ-GAUDIANO; LORENZETTI, 2009, dentre outros).

Há um esforço de trabalho para indicar as peculiaridades dos países ditos latinos no campo da pesquisa em EA, enfatizando aspectos como as intensas desigualdades, o processo de marginalização e aniquilamento dos povos originários, as diásporas de grupos culturais escravizados de outros continentes, bem como a condição de colonizados no período Moderno, os quais trazem, no seu bojo, a demanda por uma produção em EA que considere a inversão dessa condição de colonização de exploração ambiental, social, cultural e da manutenção de uma monocultura dos saber, chanceladas, principalmente, pelo conhecimento científico.

Segundo Veras Neto e Santos (2011), a partir de 2001 e, mais incisivamente, a partir de 2009, acompanha-se um intenso movimento de intenção neocolonizadora dos países ditos do Norte com estratégias de integração regional em blocos econômicos tais como ALCA (Área de Livre Comércio das Américas) e ASPAN (Aliança para Segurança e Prosperidade da América do Norte). Dessa forma, a busca por uma EA crítica e comprometida com a realidade latino-americana se faz a partir da valorização das culturas dos povos originários e da luta contra a exclusão cultural, historicamente presente nessa relação colonial.

Nesse mesmo período, foi possível acompanhar mudanças no enfoque das discussões da Educação Popular nos países latino-americanos. Surgiu uma vertente que se desloca do posicionamento frente aos totalitarismos, e voltada à democratização dos sistemas políticos, para uma engajada proposta de superação das homogeneizações provenientes dos discursos coloniais dominantes. Segundo Mejía (2017) a homogeneização biótica, cultural e pedagógica forma a tríade que deve ser superada pelos processos educativos engajados com a diversidade biológica e cultural.

O sentido de uma educação transformadora e emancipadora ganha contornos de luta contra a globalização perversa, já descrita por Santos (2006), e busca, na diferença cultural e negociação dos saberes, a possibilidade da superação do discurso hegemônico que cooptou não só a ideia de democracia, mas, também, propostas progressistas de transformação social. Nesse sentido,Nahmías (2006) utiliza a expressão pedagogizar a diversidade cultural, de maneira que ela se estabeleça em todas as dimensões nas quais ela se manifesta, e, além disso, investigar de que maneira essas dimensões se relacionam com as práticas educativas.

Como a pesquisa em Educação Ambiental e a perspectiva da Educação Popular, principalmente na figura de Paulo Freire (1921/1997), se aproximam a partir de sua vertente crítica e transformadora, nota-se que para a emergência da interculturalidade como princípio teórico/prático desponta como caminho para o enfrentamento das adversidades do capitalismo cognitivo, predominante na contemporaneidade. Assumindo a interculturalidade como meta para o enfrentamento das homogeneizações da globalização, do discurso colonial hegemônico, visando a superação das desigualdades e marginalizações socioambientais, encontra-se, na discussão mais atual entre a EA e a Educação Popular, a demanda por estudos que contemplem tais questões agudas e emergentes da sociedade contemporânea. Nesse contexto, é importante ressaltar que a interculturalidade é motivo de discussões não apenas no âmbito escolar, mas está diretamente relacionada ao contexto da realidade dos países latinoamericanos.

Apesar de o termo interculturalidade remeter à ideia de entre culturas, uma análise mais aprofundada dos aspectos teóricos revela que a discussão não se restringe a um mero contato entre diferentes culturas. Trata-se de um intercâmbio que se estabelece em condições 
de igualdade. Deve ser compreendida enquanto processo permanente de relação, comunicação e aprendizagem entre pessoas, grupos, conhecimentos e valores distintos (WALSH, 2010). A aposta teórica é de construção de uma relação mais horizontal e de perturbação dos topos enunciativos que mantêm a condição de dominação.

Aqui, é importante salientar que o termo multicultural apareceu somente uma vez,num trabalho de 2015. A não observância da mesma frequência do termo, quando comparada ao termo interculturaldeve ser atribuída à distinção teórica entre as diferentes vertentes da interculturalidade. Segundo Walsh (2010) a interculturalidade crítica se distingue do multiculturalismo, que busca uma visão integracionista ou funcionalista perante a diversidade cultural.

Em outras palavras, a perspectiva crítica da interculturalidade aproxima-se da vertente de Bhabha (2005) que desloca o enfoque para a categoria de diferença, ao invés da diversidade cultural. Assim, o multiculturalismo não aparecer como termo significativo pode reforçar, ainda mais,a proposta de posicionamento teórico que considere as desigualdades e marginalizações encontradas na América Latina, vislumbrando possibilidades pedagógicas da diferença cultural com vistas a negociações de saberes que permitam a inversão colonial.

Nessa perspectiva teórica, é importante ressaltar que o termo colonial, que aparece com frequência importante na Tabela 1, pode ser visto nos trabalhos acompanhado de prefixos ou sufixos, constituindo novos conceitos teóricos. Termos como colonialidade e decolonialidade, assim como giro decolonial, são cada vez mais frequentes no cerne da discussão aqui delineada. Essa perspectiva considera a possibilidade de inversão discursiva dos valores coloniais dominantes, a partir da valorização e da consideração dos saberes tradicionais na pauta do dia.

Por isso, ao identificar o termo diálogos de saberes é importante definir, do ponto de vista teórico, o posicionamento dos trabalhos inclusos nesse enfoque. Não há uma definição única sobre o saber popular, contudo é possível localizar esse debate no mesmo contexto de esforços para a superação de um discurso hegemônico, da luta contra a dominação de um grupo cultural sobre outros historicamente subalternizados. Assim, a negociação de saberes frente a situações que permitam o espaço-tempo híbrido, intersticial ou, ainda, que promova os entre lugares nas palavras de Bhabha (2005), são condições fundamentais para a desestabilização da potente semiótica do discurso colonial.

Segundo Chassot (2004) o saber popular é transmitido de geração para geração, solidariamente e baseado em muita empiria. Já para Gondim (2007), são conhecimentos obtidos empiricamente, a partir do fazer, que são transmitidos e validados de geração em geração, principalmente por meio da linguagem oral, de gestos e atitudes, e que são colocados à margem da sociedade. Dessa forma, ao enunciar as possibilidades de diálogos de saberes nos trabalhos analisados, vislumbra-se uma posição de valorização do diálogo nos processos educativos como forma de provocar fissuras nos discursos dominantes que permeiam os ambientes educacionais e silenciam diferentes grupos culturais. Trata-se de desconstruir uma única forma de propagar o conhecimento, baseado na ciência como único saber válido, para explorar outras formas de conhecer, valorizando a diferença cultural a partir dos saberes tradicionais.

Com os processos de silenciamento, aculturação e anomia cultural promovidos pelo discurso colonial, a negociação de saberes surge como proposta de horizontalização dos diálogos. O saber popular que preserva valores, vivências e, sobretudo, experiências passadas entre gerações desponta como forma de considerar diferentes cosmovisões na construção do conhecimento. Quando se pensa na educação ambiental, vislumbra-se que conhecer tais aspectos e colocá-los em diálogo com o conhecimento científico torna-se muito enriquecedor para os processos educativos. 
Em certa medida, trabalhos que investigam saberes culturais de grupos específicos estão presentes na Educação Ambiental brasileira desde o início da realização dos encontros Epea. Rink e Megid-Neto (2009, p. 249), em trabalho que se refere às quatro primeiras edições do Epea, afirmam que havia muitos trabalhos voltados para as concepções de indivíduos:

\begin{abstract}
Os estudos mais presentes no conjunto dos documentos dos EPEAs são aqueles classificados em Características e Concepções de Indivíduos, com 112 trabalhos (37\%) no conjunto dos quatro EPEAs. Esses trabalhos realizam um perfil sociográfico do indivíduo (aluno, professor, educador ambiental, outros profissionais, público em geral), de seu conhecimento "espontâneo", de suas concepções, sentidos, ideias e representações sobre ambiente, saúde, Educação, da própria EA, entre outros. Também foram encontrados alguns diagnósticos das condições socioeconômicas e culturais de alunos, professores, agentes educadores ambientais ou público em geral, além de diagnósticos da prática pedagógica de um profissional ou grupo de profissionais, explicitando suas idiossincrasias e concepções do processo educacional ou, mais particularmente, da EA.
\end{abstract}

Esses dados parecem indicar uma visão de que a cultura dos alunos é vista de forma generalizadora, pois o foco dos trabalhos das 4 primeiras edições do Epeas era centrado nos indivíduos e nas suas concepções, e não na problematização da relação entre as práticas de educação ambiental e as culturas dos alunos. A cultura seria vista como elemento de diagnóstico, não trazendo uma preocupação com a problematização das relações entre as culturas e como elas são perpassadas por relações de poder.

É importante buscar entender, também, em que sentido os trabalhos de EA discutiam Estudos Culturais, identidades e saberes descolado de uma perspectiva intercultural, multicultural e/ou decolonial. Acreditamos que esse caminho possa apontar uma possível compreensão desse esvaziamento do GDPPesquisa em Educação Ambiental e Culturas.

Também, parece interessante analisar em que medida o predomínio atual de trabalhos que focam outros saberes e questões ligadas à (de)colonialidade nas relações entre saberes reflete uma tendência mais ampla dos estudos que se voltam para as culturas locais, para as culturas particulares, ou seja, se indica uma mudança de uma perspectiva da cultura no singular para a cultura no plural, no sentido do termo usado por Michel de Certeau (CERTEAU, 1995).

Sendo assim, ao identificar as mudanças de termos, presentes com maior frequência nos trabalhos submetidos nas três últimas edições do EPEA, é possível inferirque tem ocorrido uma mudança de significações sobre o eixo Educação Ambiental e Culturas. Assumindo os estudos culturais, ou o debate em aberto da pós-modernidade, frente às perspectivas ditas críticas dos processos educativos, nota-se uma vertente emergente dessa polarização: uma perspectiva mais pós-colonial que pós-moderna, com um olhar que tende a pensar o intelectual orgânico gramsciano no sentido de uma produção desde as epistemologias do Sul (SANTOS, 2010).

\title{
Referências
}

BHABHA, H. K. O local da cultura. Belo Horizonte: Ed. UFMG, 2005.

CERTEAU, M. A cultura no plural. Campinas:Papirus, 1995.

CHASSOT, A. Saberes Populares fazendo-se saberes escolares: uma alternativa para a alfabetização científica. In: SEMINÁRIO DE PESQUISA EM EDUCAÇÃO DA REGIÃO SUL, 5, 2004, Curitiba. Anais... Curitiba: Pontifícia Universidade Católica do Paraná, 2004. 
FERREIRA, N. S. A.As pesquisas denominadas "estado da arte". Educ. Soc., Campinas, v. 23, n. 79, p. 257-272, ago.2002.

GONDIM, M. S. C. A inter-relação entre saberes científicos e saberes populares na escola: uma proposta interdisciplinar baseada em saberes das artesãs do Triângulo Mineiro. 2007. 174 f. Dissertação (Mestrado Profissionalizante em Ensino de Ciências) - Programa de Pós-Graduação em Ensino de Ciências, Universidade de Brasília, Brasília, 2007.

GEERTZ, C.A interpretação das culturas.São Paulo: LTC, 1989.

GONZALEZ-GAUDIANO, E.; LORENZETTI, L. Investigação em Educação Ambiental na América Latina: mapeando tendências. Educ. rev., Belo Horizonte, v. 25, n. 3, p. 191-211, Dec.2009. Disponível em: <http://www.scielo.br/pdf/edur/v25n3/10.pdf>. Acesso em: 5 mai. 2018.

GUIDO, L. F. E.Apresentação das discussões do GDP Pesquisa em Educação Ambiental e Culturas. Apresentação em arquivo de formato digital (.ppt) exibida na sessão de discussão dos GDPs do VII Epea, realizado em Rio Claro (SP), de 7 a 10 de julho de 2013.

GUIMARÃES, L. B.; WORTMANN, M. L. C.Educação ambiental e estudos culturais: pesquisas desde o Sul do Brasil. Pesquisa em Educação Ambiental, Rio Claro, v. 9, n. 1, p. 24-37, jan-jun, 2014.

LAYRARGUES, P. P; LIMA, G. F. C. Mapeando as macrotendênciaspolítico-pedagógicas da Educação Ambiental contemporânea no Brasil. In: ENCONTRO PESQUISA EM EDUCAÇÃO AMBIENTAL, 6, 2011, Ribeirão Preto. Anais...Ribeirão Preto: USP, 2011. p. 1-15. Disponível em: http://www.epea.tmp.br/viepea/epea2011_anais/busca/index.html. Acesso em: 11/06/2018.

LEFF, E. Saber ambiental:sustentabilidade, racionalidade, complexidade, poder. Tradução de Lúcia Mathilde Endlich Orth. 8ed.Petrópolis: Vozes, 2011.

MEJÍA, M.R.J. La globalización capitalista y el lugar epistémico de laeducación popular en América Latina (entrevista). Revista eletrônica Cadernos Cimeac, Uberaba, v. 7, n.2, p.8-35, dez. 2017. Disponível em: http://seer.uftm.edu.br/revistaeletronica/index.php/cimeac/article/view/2488/2394. Acesso em: 11/06/2018.

NAHMÍAS, M. T. Os Desafios da Educação Popular Frente à Diversidade e à Exclusão. In: PONTUAL, P.; IRELAND, T. (Orgs.). Educação Popular na América Latina:diálogos e perspectivas.Brasília: Edições MEC/Unesco, 2006. p. 123-134.

RINK, J.; MEGID NETO, J. Tendências dos artigos apresentados nos Encontros de Pesquisa em Educação Ambiental (EPEA). Educ. rev.,Belo Horizonte, v. 25, n. 3, p. 235-263, dez. 2009. Disponível em: < http://www.scielo.br/pdf/edur/v25n3/12.pdf>. Acesso em: 6 mai. 2018.

SANTOS, B. S. Para além do pensamento abissal: das linhas globais a uma ecologia dos saberes. In SANTOS, B. S.; MENESES, M. P. ()rgs.). Epistemologias do Sul. São Paulo: Cortez, 2010. p. 31-83.

SANTOS, M. Por uma outra globalização - do pensamento único à consciência universal. Rio de Janeiro: Record, 2006.

VERAS NETO, F. Q.; DOS SANTOS, T. F.América Latina: as possibilidades à educação ambiental em uma nova conjuntura geopolítica. Revista Eletrônica do Mestrado em Educação Ambiental, Rio Grande (RS), v. 27, p. 196-209, jul-dez. 2011. Disponível em: https://periodicos.furg.br/remea/article/view/3237. Acesso em 11/06/2018. 
WALSH, C. Estudios (inter)culturalesen clave de-colonial. Tabula Rasa, Bogotá, n. 12, p. 209-227, ene-jun 2010. 